Article

\title{
Oceans without History? Marine Cultural Heritage and the Sustainable Development Agenda
}

\section{Jon Henderson $\mathbb{B}$}

Underwater Archaeology Research Centre, Department of Classics and Archaeology, University of Nottingham, Nottingham NG7 2QL, UK; jon.henderson@nottingham.ac.uk

Received: 13 August 2019; Accepted: 12 September 2019; Published: 17 September 2019

check for updates

\begin{abstract}
This paper aims to set out the role Marine Cultural Heritage (MCH) can play in informing responses to global challenges and enhancing the sustainable development of coastal zones. This requires recognition of the importance of $\mathrm{MCH}$ as a knowledge base amongst marine ocean scientists, policy makers and marine stakeholders on the one hand and a greater effort by marine heritage specialists to engage with the 2030 Agenda on the other. The forthcoming UN Decade of Ocean Science for Sustainable Development (2021-2030) provides an opportunity to engage with the sea more widely but it is argued that the cultural element provided by considering past human action is currently lacking. The importance of understanding human interaction with the sea in terms of gaining a more complete picture of human history is briefly presented and a definition of $\mathrm{MCH}$ as all past action in the human zone is given. The article then sets out how $\mathrm{MCH}$ can enhance sustainable development in the marine zone with particular reference to SDG14 considering heritage tourism, coastal development and infrastructure, development aid policy, climate change, coastal management, fisheries and the offshore industry. The article highlights that the knowledge and data from $\mathrm{MCH}$ should be seen as crucial in evidence-based decision making across the coastal and marine sectors. The paper concludes that the inclusion of $\mathrm{MCH}$ approaches in initiatives aiming at coastal and ocean sustainability is not just advisable-it is essential.
\end{abstract}

Keywords: Marine Cultural Heritage; maritime archaeology; sustainable development; SDG 14; resilience; Blue Economy; Ocean Science

\section{Introduction}

The 2030 Agenda for Sustainable Development sets out 17 Sustainable Development Goals (SDGs) to address the multiple and complex challenges our planet faces in the twenty-first century [1]. SDG 14, Life Below Water, is a key goal of the 2030 Agenda with its stated aim to 'Conserve and sustainably use the oceans, seas and marine resources for sustainable development' while, more broadly, a concern with healthy oceans and sustainable coastal activity runs through many of the SDGs. Simply put, ensuring sustainable oceans and seas is critical to sustaining human life. Our very survival as a species is dependent upon healthy oceans and seas as they provide half of the world's oxygen, store carbon dioxide, and contain 80 percent of life on the planet [2]. They also supply a major food source, upon which more than 3.1 billion people depend to provide at least 20 percent of their daily protein intake, and they directly support the livelihoods of $10 \%$ to $12 \%$ of the world's population [2], pp. $6-8$. Although there is a recognition that oceans and seas play an important role in human well-being, and that activity on and around them (particularly related to tourism and leisure) can lead to social and economic benefits, the long-term cultural importance of the marine environment remains largely unrecognised. In particular, the potential role of marine heritage in helping to achieve the goals of SDG14 remains untapped. This paper aims to set out the role that Marine Cultural Heritage can play in informing responses to global challenges and enhancing the sustainable development of coastal zones. 
The United Nations SDGs are setting the global agenda and are going to be instrumental to national academic research strategies and, in turn, research funding support up until at least 2030. If maritime archaeology is to progress, establish itself in modern practice, and realise its full potential, then it needs to respond to the 2030 Agenda. As a unique resource with knowledge and experience that can contribute to the goal of sustainable development in the marine zone, the importance of marine cultural heritage has so far been completely neglected. This is perhaps unsurprising given the maritime archaeological community has not so far directly addressed the 2030 Agenda and is, instead, viewed from outside the profession as focussing on the preservation and protection of the resource rather than what it can offer in terms of economic, social and cultural benefits. As a result, maritime archaeology is a resource-poor discipline which is seen by many governments and institutions as a further financial burden they can ill afford.

The problem is two-fold: while maritime and coastal archaeologists are not addressing the challenges set out in the SDGs, the SDGs themselves do not consider marine cultural heritage as an important aspect in achieving coastal and ocean sustainability. While the SDGs have been commended for mentioning the importance of culture in a development context for the first time, it could be argued that they do not go far enough in stressing the central role of culture in achieving human-centred, inclusive and ethical development. In fact, 'cultural heritage' is only directly referred to twice in the text accompanying the 17 development goals and their 169 targets, with no single goal emphasising the need to identify and incorporate traditional and past human practices into sustainable management plans.

The next decade has been termed the Decade of Ocean Science for Sustainable Development 2021-2030, a UN initiative that aims to create a common framework for supporting stakeholders in studying and assessing the health of the world's oceans. Although the 'Roadmap' for the initiative states that, "'Ocean Science' should be interpreted broadly as encompassing: social sciences and human dimensions" there is no consideration of maritime archaeology or the importance of marine heritage in the 51-page document [3]. The rich data sets that maritime archaeological approaches can provide are current being overlooked and the subject is in danger of being left behind.

The implications of the current state of affairs are potentially calamitous. As long as the importance of cultural heritage is not recognised as a critical and valuable knowledge base, sustainable development initiatives in the marine zone will be less likely to succeed and, worse, will undermine the identities and wellbeing of coastal communities.

\section{Seeing the Sea: The Sea as a Connector}

The social, economic and cultural progress of humanity has always been closely connected to the sea. From the spread of human groups in early prehistory to the importance of container shipping and maritime commerce to modern economies today, sea travel has remained central to the development and maintenance of human societies. It seems odd then that it enjoys, at best, a supporting role in dominant historical narratives. In such narratives, it is common to read about the industrial and agricultural revolutions with little or no mention of the vital seafaring revolution that took place long before them [4-6]. In this modern age of air travel, it is perhaps all too easy to underestimate the role of the sea. It is somewhat ironic that as global sea levels continue to rise, an awareness of the sea as a driver of human change and development has fallen at a similarly dramatic rate. This may seem odd given the importance of the sea to human life and development but it reflects a long held, and hard to break, conceptual division between land and sea prevalent globally in academia, legislation, government and public perception.

The separation of land and sea as conceptual and physical entities may seem to be one of the most basic and non-problematic divisions of the natural world but it is ultimately responsible for the underappreciated role of the importance of the sea in human history. Terrestrial heritage takes precedence and is dominant in historical narratives, while marine and underwater heritage is usually regarded as supplemental and optional. Despite the fact that pioneers such as George Bass [7] recognised from the outset that maritime archaeology should not be viewed as a separate 
subject or distant cousin to archaeology carried out on land, it is still widely regarded as an exotic add-on to 'mainstream' terrestrial research. Archaeologists continue to be labelled 'underwater' or 'maritime' archaeologists if their research involves work in the sea, the implication being that maritime archaeology is something apart from the archaeological 'mainstream' on land-something glamorous and adventurous but not fundamental to the discipline, something not to be taken too seriously.

Although it should be self-evident that studying past human interaction with the sea is vital to the human past as a whole, the majority of universities still offer no, or at best limited, provision in maritime archaeology. Equally, the capacity for nations to fully record, study and protect their marine heritage through professional services remains far behind that of terrestrial capacity, especially in developing countries and Small Island Developing States (SIDS) where the threats to that heritage are often more intense.

The separation of terrestrial and maritime approaches has masked the importance of the sea to developments on land and has made it easier for terrestrial and maritime archaeologists and historians to stay within their own information silos. Although the situation is improving [8], maritime archaeologists still tend to talk to other maritime archaeologists at specialised conferences where often the only aspect uniting their research is the environment in which they work. This has inevitably led to either myopic discussions focusing on individual sites or artefact groups in isolation (still a problem in shipwreck archaeology) or to wider discussions being limited to methodologies, new technologies, legislation and protection rather than the development of wider ranging historical narratives, research themes or theoretical debates [9].

More widely, UNESCO consider underwater and terrestrial heritage in different departments, as do most government bodies, funding bodies and organisations. The UNESCO focus on protecting underwater cultural heritage, through encouraging member states to sign the 2001 Convention on the Protection of the Underwater Cultural Heritage [10], has the unintended consequence of removing underwater heritage from wider heritage discourse. Maritime archaeology is generally not considered in World Heritage debates - and even when it is, talk is often of isolated marine 'treasures' which can be counter-productive [11]. Perhaps it is no surprise then that UNESCO have identified public, scientific and political awareness as one of the fundamental issues to tackle in an effort to increase the protection of underwater cultural heritage (UCH) worldwide (Article 20 of the 2001 Convention). Certainly, underwater cultural heritage is different from terrestrial heritage in that unless they can scuba dive the vast majority of people have never even seen it first-hand. As a result, and in direct contrast to terrestrial heritage, few communities are aware of the historical context or value of maritime archaeology.

This artificial separation between maritime and terrestrial affairs permeates throughout human bureaucracy. Legal structures and laws are different when we reach the shoreline-traditionally land and sea are treated differently. Clearly, we need a more joined up cultural approach to the sea that fully recognises its central role in the development of human societies past and present. Just as the sea connected communities in the past, it should serve to connect scientific approaches, management approaches, historical narratives, and human activities in the maritime space today.

\section{Marine Cultural Heritage: Overcoming the Land/Sea Division}

Over the years, the reach of maritime archaeology has broadened from the study of individual shipwrecks to the consideration of entire maritime cultural landscapes [12,13]. The concept of the maritime cultural landscape was introduced in 1992 by Christer Westerdahl to provide a more comprehensive understanding of maritime archaeology through the study of the 'human utilization of maritime space by boat: settlement, fishing, hunting, shipping and its attendant subcultures' [12], p. 5 . The incorporation of coastal monuments and traditions not only enhanced the understanding of underwater sites but also maritime culture more widely. Crucially, maritime cultural landscape approaches link the land and sea together to embrace the totality of the potential space affected by human maritime action $[14,15]$. This maritime space can be both physical and conceptual in that it 'should include any hermeneutic kind of human relationship to the sea' [16]. 
Building on the marine cultural landscape concept, all past human action on the coasts as well as directly on the sea can be combined to constitute Marine Cultural Heritage. There is little to be gained in dividing land and sea-human involvement with the sea did not begin and end at the shoreline. As such, Marine Cultural Heritage ( $\mathrm{MCH}$ ) encompasses tangible remains such as shipwrecks, submerged settlements, coastal settlements, ports and harbours, maritime ecologies, and geology as well as equally vital intangible components such as cultural practices, artistic and linguistic expressions, local skills, traditional and historical knowledge. The reach of $\mathrm{MCH}$ is then similarly broad and includes its relationship to economic development, environmental management, social justice, education and identity. 'Marine' is the preferred adjective here as it relates to all things pertaining to the sea and as such encompasses all activity associated with the oceans while 'maritime' is usually used in a more restricted sense to refer to sea travel, shipping and exploration. 'Marine' also fits in with the terminology used in the Ocean Sciences and by marine stakeholders in spatial planning, conservation, tourism, ecological services, engineering and development more generally. 'Marine' is not used to negate or replace the term 'maritime' as it is used in archaeological contexts but rather to flag the relevance and utility of heritage as a usable knowledge base to current marine stakeholders who might not otherwise think it is relevant to their activities.

Ultimately, $\mathrm{MCH}$ is concerned with human relationships (physical, cultural and conceptual) with the sea and as such it is an essential part of understanding the human past. Interaction with the sea and, in particular, the development of seafaring is a fundamental part of the human experience-indeed, it was the development of seafaring that set us apart from our ancestors [17].

We are only just beginning to fully appreciate how crucial the sea was in terms of human development. For example, the relatively recent realisation that sea levels were up to $130 \mathrm{~m}$ lower at the height of last glacial maximum $(26,000 \mathrm{BP})$ reaching present day levels only around 5000 years ago has begun to garner the attention of terrestrial archaeologists (Figure 1). Vast swathes of the coast where prehistoric populations would have settled 30,000 to 5000 years ago to exploit as wide a variety of resources as possible are now underwater [18]. Most of the major events in world prehistory occurred when sea levels were much lower than today including the global dispersal of our own species, development of our cognitive powers, fishing and seafaring, navigation, maritime trade, the origins and expansion of farming, and the beginnings of the first civilisations in the Near East and the Mediterranean [19]. It goes without saying that existing accounts of world prehistory are severely lacking without taking submerged coastal areas into account in the same way that it would be impossible to understand modern society without referring to coastal cities like New York, Rio de Janeiro, London, Mumbai, Singapore, Hong Kong, Shanghai or Sydney. 

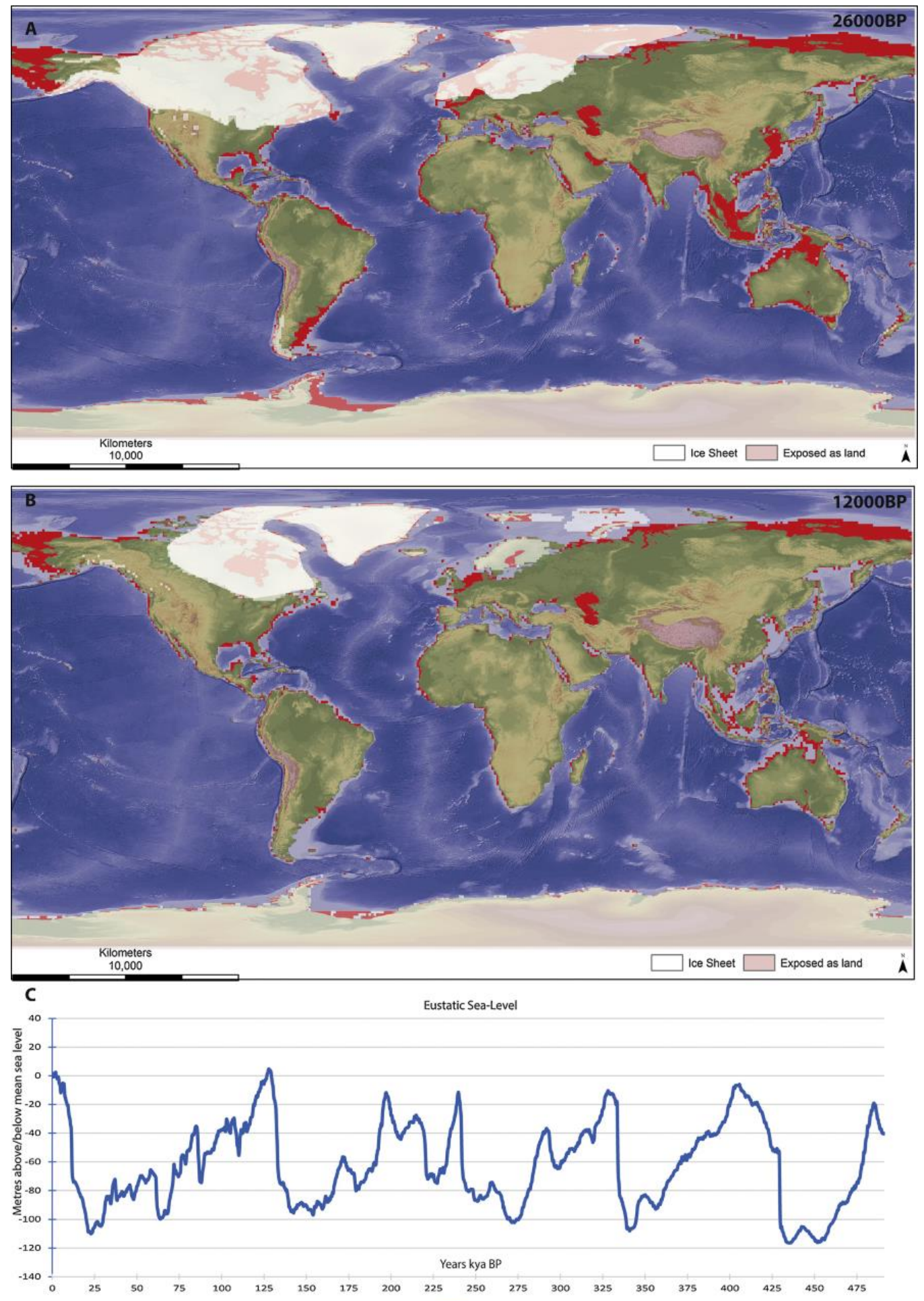

Figure 1. Global sea level at the height of the last glacial maximum $(26,000 \mathrm{BP})$ and end of the last Ice Age and beginning of the Holocene (12,000 BP) [20]. Land that is now underwater marked in red (diagram by Fraser Sturt).

As is the case with the focus of infrastructural development today, coasts were key areas in the past where human development happened. They were not boundaries or marginal spaces but were (and continue to be) theatres of innovation-human coastal settlements were key nodes of interaction where contacts and communications were negotiated and major technological advances were made. Strategies for the sustainable development of coastal areas is a key issue today-archaeological 
approaches can provide data on human activity along the coasts over millennia which can help inform future strategies.

Marine Cultural Heritage ( $\mathrm{MCH}$ ) has the potential to bring widespread and sustainable benefits to coastal regions. Globally, the potential and importance of $\mathrm{MCH}$ has not yet been realised. Critically, it is under threat everywhere, not only from commercial exploitation and illegal looting (which signing the 2001 convention mitigates against) but also from natural forces and climate driven coastal change as well as intensification in coastal and offshore development. We are losing the $\mathrm{MCH}$ resource before we have had a chance to harness its potential. Local capacity to utilise $\mathrm{MCH}$, particularly in developing countries and SIDS, is limited and urgently needs enhancing through investment in ethical sustainable development programmes.

\section{The Challenge: SDG 14 and Sustainable Ocean Management}

With its focus on conservation and the sustainable use of marine resources, SDG14 is concerned with current and future human interaction with the oceans. The key SDG14 targets and indicators are set to mitigate against five main threats: unsustainable fishing practices, loss of coastal and ocean habitats, invasive species, pollution, and the effects of climate change. As well as stressing the vital role healthy oceans perform in stabilising climate and supporting life on earth, SDG14 recognises the potential economic and social benefits that sustainable use of marine resources can provide. These benefits are normally expressed as enhanced food security, sustainable energy generation, poverty eradication through marine orientated livelihoods, as well as the development of coastal and marine tourism.

Sustainable ocean management is seen as key to achieving the aims of SDG14. Traditionally, such management strategies have been driven by purely scientific solutions and/or economists seeking to make practices more efficient through adding a tangible monetary return [21,22]. The latter has led to the concepts of a 'Blue Economy' or 'Blue Growth' entering into common policy usage in an international context. The creation of a 'Blue Economy' is a key approach in the sustainable use of the oceans that has been embraced in particular by Small Island Developing States such as Grenada [23-26] but is applicable to the utilisation of coastal areas worldwide. A 'Blue Economy' is one that uses ocean resources sustainably to create jobs, promote economic growth and enhance social inclusion while also improving ocean ecosystem health. Creating an effective blue economic strategy involves creating economic benefits from a range of marine activities centred on clean technologies, ethical ocean waste management, renewable energy, climate change mitigation, viable seabed extractive activities, sustainable fisheries, effective aquaculture and enhanced coastal tourism.

While environmental sciences and ecological approaches have had a major role in the development of the 'Blue Economy' concept, and indeed remain the focus of SDG14, the potential role of marine heritage has not been considered beyond paying lip-service to the role of archaeology and heritage in the enhancement of coastal tourism.

However, as people and communities remain at the centre of development, there is a growing awareness that the arts, humanities and social sciences have a key role to play in the development of effective management strategies, especially if those strategies are going to be sustainable.

In her 2014 TED talk on Sustainable Ocean Management, Nicola Crane used the following quote:

We need to have a common understanding around management, so that everyone agrees and supports it. Understanding the old ways, and the impacts of the new ways, can help protects the oceans for our children, and their children.

She was not quoting an academic or development specialist but a local chief from Asor Island on Ulithi Athol, Micronesia, who was addressing his community about proposed conservation practices. As she points out, he does not tell his people what to do because he understands that if he enforces a plan there is a good chance it could fail. Instead, he tries to get the support of the community around a common problem they all face and, significantly, makes reference to past practice as well as future 
action. As a member of the community, he fully understands the importance of cultural context and that an awareness and mediation of local practice is crucial to establishing any meaningful activity.

Achieving effective conservation practices and sustainable economic development requires a cultural awareness and respect for the communities in the areas where development is taking place. People are at the centre of any sustainable development initiative and it is their direct action that enables change to take place. Solutions cannot be simply imposed from outside-no matter how strong the scientific evidence to support them-without the active involvement and support of local people. In 2015, UK aid supported a $£ 6$ million African Development Bank project to build high-tech landing platforms in coastal villages in Madagascar to modernise traditional fishing practices. The initiative failed as the platforms were never used. A subsequent report by the Independent Commission for Aid Impact (Icai) revealed that these platforms were not being used due to a failure to consult with local communities as to what they actually wanted [27]. The science behind platforms was sound but a lack of consideration of cultural context and particularly a lack of understanding of local fishing traditions resulted in the failure of the initiative.

If nothing else, $\mathrm{MCH}$ has a key role to play achieving successful sustainable development in that it can provide a deep awareness of local traditions and practice. Too often Western perspectives drive ocean conservation and sustainable management plans worldwide. Coastal communities in developing countries are expected to adopt plans that Western scientists came up with, without taking into account that these communities have been living by the sea successfully for thousands of years. Equally the problems these communities are now experiencing are most often a result of the actions of the Global North rather than their own cultural practices. We need to recognise this and avoid 'sustainable development' being a stand-in for neo-colonialism with initiatives implemented by academics and scientists from the Global North with no involvement from local communities and limited knowledge of existing and past traditions.

Having an awareness of local community beliefs, heritage and culture should be at the core of developing new sustainable ways of living. Local ecological knowledge and cultural practice (past and present) are drivers of change-as such, local communities should have a voice in the creation of development projects with a clear recognition that their knowledge can inform those projects and ultimately make them more sustainable.

\subsection{Marine Heritage Tourism}

The usual link made between cultural heritage and economic development is heritage tourism [28,29]. Tourism is one of the strongest drivers of world trade and a major tool for poverty alleviation with cultural tourism, in particular, accounting for $40 \%$ of world tourism revenues [30]. As a labour-intensive sector, tourism can have a positive impact on low-income and disadvantaged groups who form a crucial part of the tourism supply chain. Data from the UN World Tourism Agency (UNWTO) show that tourism activity in developing countries accounts for $47 \%$ of global tourism as a whole [31]. However, to date, the coastal tourism of developing countries and SIDS has tended to concentrate on natural resources such as marine life and coral reefs: $\mathrm{MCH}$ as a resource has been underdeveloped and undervalued.

There is a growing recognition that submerged cultural heritage such as shipwrecks or sunken settlements can open up coastal tourism opportunities in terms of recreational diving [32-34]. For example, the shipwrecks of the Egyptian Red Sea are a major attraction for divers from all over the world and are an important economic asset for the country. Recreational diving on the SS Thistlegorm-widely regarded as one of the most spectacular wreck dives in the region-brings an estimated 4 million euros into the local economy every year [35] (Figure 2). Worldwide, national authorities are creating dive trails and submerged archaeological parks to nurture diving tourism economies [36-39]. This is of special importance for developing countries adjacent to the ocean and SIDS, who can greatly enhance their tourist attractiveness through the discovery, quantification and presentation of their underwater resource [40]. 


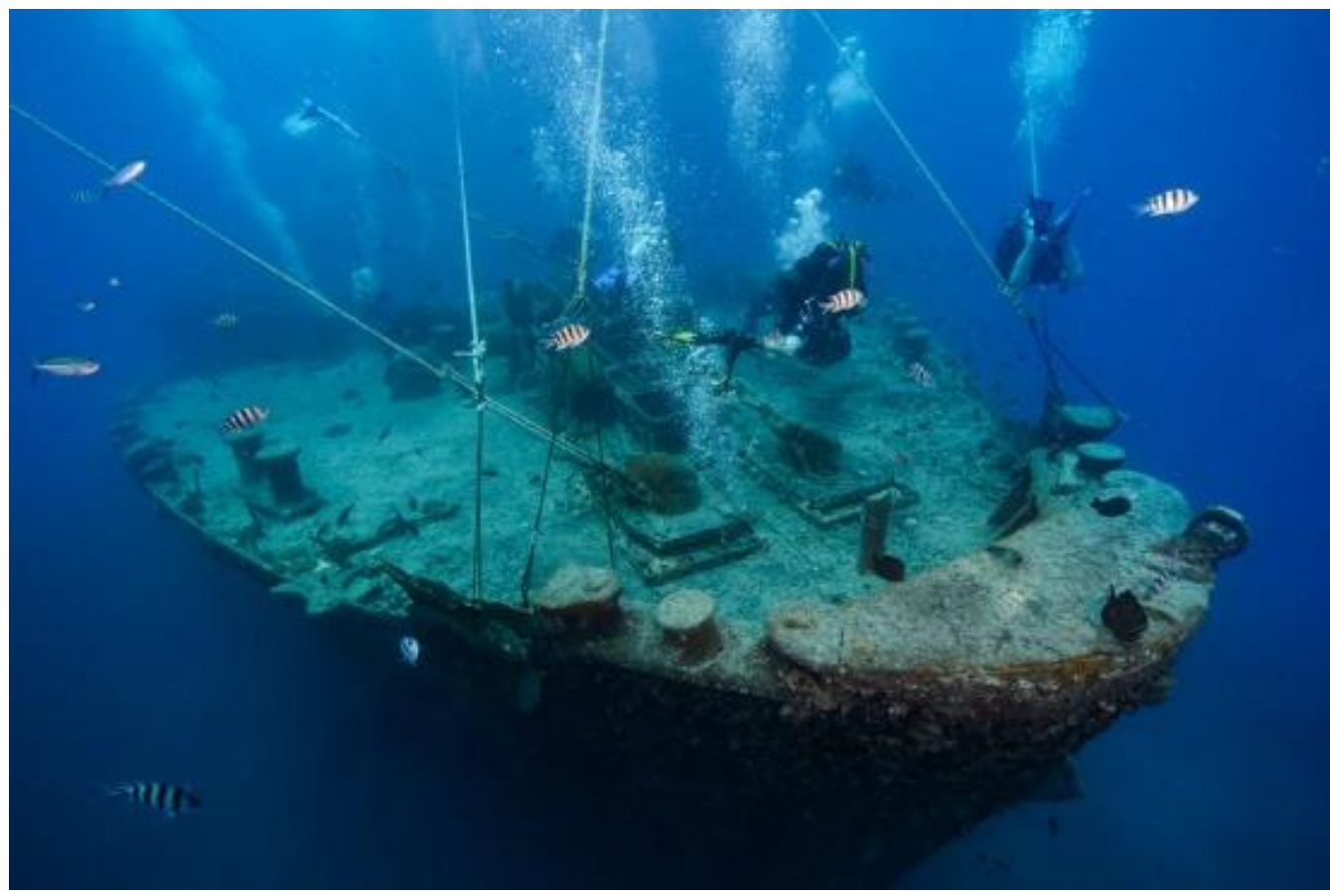

Figure 2. The popularity of the SS Thistlegorm in the Red Sea as a dive tourism location has come at a cost. Up to eight dive charter vessels each carrying around 25 divers visit the site daily over the summer season. These vessels weighing over 40 tonnes attach their mooring lines directly on to the superstructure of the wreck resulting in sustained damage. Current activity is unsustainable and a management plan for continuing tourism on the site is needed (Photo credit: Alex Mustard).

Equally, investment in museums conserving and exhibiting marine heritage can also bring beneficial and sustainable economic returns [41]. Studies show that 'every USD invested in heritage increases the economic activity around the site by a factor between 1.2 to 8 , depending on the significance of the site and the form of its valorization by museums and individual access' [42]. When presented in an accessible and sustainable way, marine heritage is a significant tourist draw, attracting millions of people. For example, the Swedish Tourist Board has estimated that the salvaged Swedish 17th century AD warship Vasa has contributed hundreds of millions of dollars into the Swedish economy since its recovery in 1961 [43]. The Vasa Museum in Stockholm, which houses the largely intact hull of the vessel, was built in 1988 and is the most visited museum in Sweden, receiving more than 1 million visitors every year. These visitors spend an average of EUR 200 per day on hotels, meals and other expenses, bringing an estimated EUR 200 million (USD 260 million) increase in spending per year to Stockholm, excluding the museum entry fees [41], p. 17. In the UK, the Mary Rose Museum is rated as the top tourist attraction in Portsmouth, closely followed by HMS Victory and HMS Warrior museums ships, receiving over 300 hundred thousand visitors each year [44], whereas the SS Great Britain is the number one tourist destination in Bristol attracting over 173,500 visitors in 2013 and bringing in an income of $£ 3.7 \mathrm{~m}$ [45].

Tourism related to the $\mathrm{MCH}$ could be a significant and as yet largely unexploited driver for economic growth. However, despite this opportunity it is prudent to add a caveat here. Governments are often all too keen to harness the potential of heritage to promote and enhance coastal tourism but such activities must be done ethically and sustainably. There is a growing realisation amongst heritage practitioners that simply intensifying activity is ultimately unsustainable and detrimental to the very survival of heritage.

For example, taken as a whole the Mediterranean coasts and beaches are the most popular tourist destinations in the world. Of the 220 million tourists who visit the Mediterranean every year, over 100 million head to the beaches and this coastal tourism is vital to the economies of Mediterranean 
countries [46]. However, this mass tourism is also one of the main causes of ecological and heritage site loss in the region. Since the 1960s, there has been major infrastructural development along the coasts to support this ever expanding tourist industry which has dramatically altered the natural dynamics of coastal ecosystems and destroyed countless archaeological sites and landscapes in the process [47]. At present, more than half of the $46,000 \mathrm{~km}$ Mediterranean coastline is urbanized, mainly along the European shores, while a fifth of the coastline lies under concrete or tarmac. This has had a devastating impact on coastal and submerged heritage sites. For example, at the popular tourist island of Hvar, off Croatia, 30\% of all Prehistoric to Roman sites have been destroyed without record to make way for tourism developments and $65 \%$ of shipwrecks looted [48]. Equally, for some SIDS intensifying tourism is already exacerbating the effects of climate change and coastal erosion [49].

Managed sustainably, tourism around $\mathrm{MCH}$ represents an economic, social and cultural opportunity with transformational potential for the future growth and prosperity of Global South coastal states and SIDS where exiting coastal tourism is either predominantly land-based (beaches) or if recreational diving exits is focussed expressly on the natural environment (marine life and reefs etc.). Developing sustainable heritage tourism strategies should be a priority for marine heritage professionals both to establish the importance of the resource and to ensure its protection. That said, the reach and importance of MCH should not be simply limited to tourism—heritage is an essential part of human culture which can provide data and knowledge that can inform future human action.

\subsection{Coastal Development and Infrastructure}

Human settlements have always concentrated in the coastal zone as it offers a rich range of resources and transportation options, particularly in locations where rivers meet the sea. Today, coastal ecosystems are experiencing unprecedented levels of change from increasing population densities and rates of urbanization which are far outstripping those inland [50,51]. UN data published in 2007 indicated that just over 40\% of the world's population lived within $100 \mathrm{~km}$ (around 63 miles) of the coast. Projections expect around $58 \%$ of the world's population to be coastal by 2050 [52]. As construction and coastal infrastructure activity increases in this zone, pressure on coastal ecosystems and resources (including marine heritage) will increase.

The intensity of coastal urban development in China has been particularly high (more than three times the national rate), driven by resettlement strategies that drive coastward migration and specific national policies aimed at developing a strong marine economy $[53,54]$. The construction of new super-ports and the development of port cities as special economic zones is a key part of China's marine economic strategy. So far, heritage has had little or no role to play in this marine economy revolution other than as a tool to support territorial claims in disputed waters in the South China Sea [55].

Instead, Chinese port development projects such as the Dalian Diamond Bay regeneration, the largest port in Northeast China, are about creating entirely new and ultra-modern spaces by the sea. Dalian Bay has a rich and complex history. In 1898, it transformed from a small fishing village into a major commercial port city under Russian investment and control. In the 1930s, it passed into Japanese hands and then after the Second World War it once again fell under Russian or rather Soviet control. In 1950, the USSR handed the city over to the Chinese government with Soviet troops finally leaving the city in 1955. Dalian's cityscape used to reflect this history, with late 19th and 20th century Russian and Japanese architecture surrounded by gleaming new commercial skyscrapers. Now many of these significant historic buildings have been destroyed or are earmarked for demolition.

The focus of the Dalian Diamond Bay development work is instead on constructing a thoroughly modern city with a stated emphasis on ecological impact and sustainable design. Although the new development plan claims to 'celebrate the city's historical and industrial legacy', it follows the Chinese approach seen elsewhere along the coast-tearing buildings down and then building up rather than building on what is already there. The new city is being designed around squares (reportedly using Paris as a role model) and the construction of new spaces based around 'Axes of Prosperity' identified as Financial Services, Research and Development, Cultural and Tourism, and Production [56]. This has involved 
reclaiming land into the water with no prior archaeological assessment or survey taking place. The Dalian Bay interdisciplinary development team included architects, environmental scientists, ecologists, transport specialists and engineers but did not include heritage specialists, historians or archaeologists [57].

In failing to consider the role existing local heritage could play in informing sustainable development design and helping provide a real sense of place and identity, Dalian Bay is no different than the majority of coastal developments that are taking place across the world. It is more common for developers to view heritage as a barrier to development rather than an asset-a situation that is often not helped by the perceived primary focus of the marine archaeological community on in-situ protection. However, by not being included in development strategies not only is the value of $\mathrm{MCH}$ failing to be communicated, the resource is being destroyed before we have had a chance to record and utilise its potential.

There are other dangers in not having a strong professional heritage voice and awareness in the development process. The main 'heritage' tourism investment in Dalian has been the construction along the waterfront of what appears to be a replica of Venice replete with $4 \mathrm{~km}$ ( 2.5 miles) of canals, gondola rides, Italian architecture and frescoes (Figure 3). Although it is dubbed the 'Venice of the East' by local media, Dalian East District Corporation, the developers, instead use a bland but less culturally loaded name - the 'East Montage' - to refer to the colossal $\$ 1.26$ billion development. While admitting they took Venice as a blueprint, they claim it is not a building-by-building copy of the famed Italian town but rather a system of canals that allow visitors to pass through more than 200 'European-style castles'. What is certain is that the development has no connection with the rich maritime past of Dalian or the communities that lived and continue to live there.

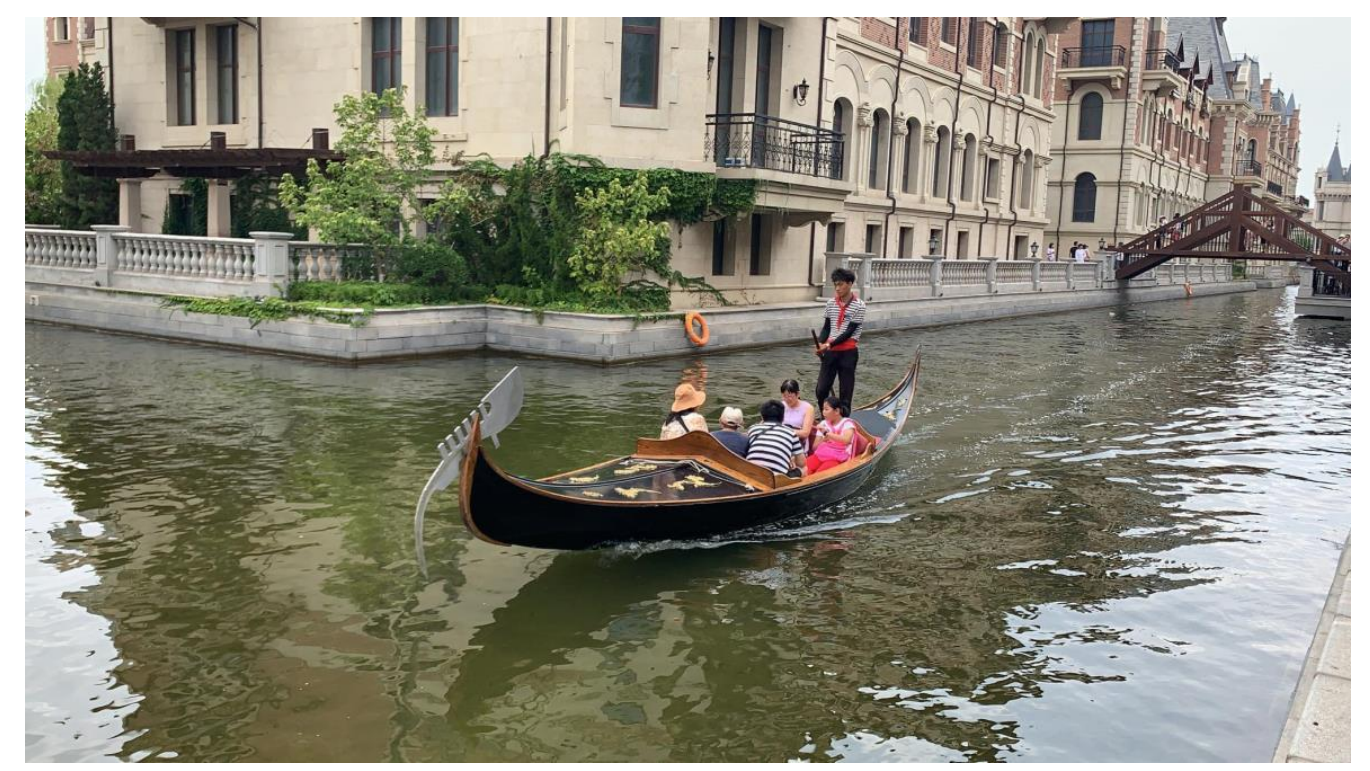

Figure 3. Welcome to Venice, China: canals, European palaces and gondoliers at Dalian (Photo credit: Sarah Ward).

Chinese port infrastructure expansion is, of course, not restricted to mainland China, the Chinese government's Belt and Road Initiative (BRI), also known as the One Belt One Road (OBOR) or the Maritime Silk Road, is a development strategy involving investment, infrastructure development and port construction in over 152 countries throughout the world [58]. Other world powers, including the US, UK, Russia and the Gulf states, are also concerned with extending their maritime influence, driven by the globalization of world economy and an urge to control maritime routes and access to energy resources as they become increasingly scarce. As a result, throughout the world $\mathrm{MCH}$ is threatened by intensifying coastal infrastructure development. 
The development of the coastal regions of East Africa provides an example of what is happening elsewhere in the world. Kenya, Tanzania and Mozambique are undergoing a period of profound change as the economy of the region gains momentum. The region's maritime zone is central to these developments with offshore exploration for oil and gas deposits driving outside investment, coupled with major financing of new and established ports to facilitate trade with the Gulf countries. In addition to aid and private investment from both the UK and other Western governments, China and Saudi Arabia are funding major infrastructural and development projects across this region. While these developments have the potential to realise short-term economic, developmental and employment benefits, there has been little consideration of the impact of this work on East Africa's outstanding but largely unstudied coastal and marine heritage.

Development aid agreements very rarely take account of cultural heritage even though access to it is considered a fundamental human right [59]. East African counties currently have little capacity to protect or explore their rich maritime heritage and, as a result, the socio-economic potential of $\mathrm{MCH}$ in the region has yet to be realised. Worse, while the submerged resource is being impacted by marine exploitation, commercial salvage and offshore industry, the coastal resource is being threatened by building and development work as well as climatic and environmental change and even some green-energy projects. $\mathrm{MCH}$ is a fragile and finite resource, which once destroyed can never be recovered.

The current threats are encapsulated in the ongoing port development work adversely affecting Lamu Old Town, a UNESCO World Heritage site in Kenya that is widely regarded as one of the oldest and best-preserved examples of Swahili settlement in East Africa [60]. In 2012, construction began on a $\$ 23$ bn ( $£ 14.5$ bn) super-port on Lamu Island which is set to include a 32-berth port, an airport, railway, motorway, an oil refinery and an oil pipeline linking Lamu to South Sudan and Ethiopia. Despite the fact that UNESCO opposed the plans stating 'there can be no doubt that a project of this scale cannot help but have profound negative impacts on the heritage of the island' [61] and, most significantly, there were extensive protests from the local community whose livelihoods rely on traditional fishing and tourism, the work proceeded.

The Lamu corridor infrastructure project is a key part of the Kenyan government's development strategy, Kenya Vision 2030 [62], which aims at transforming Kenya into an industrialising middle-income nation by 2030. They state that the project will bring benefits to the Kenyan people as a whole, citing a projected expansion of Kenya's GDP by an extra 2\%-3\%. However, it is less clear how much of this profit trickles down to local communities particularly those most at risk. In Lamu, traditional fishing accounts for around $75 \%$ of the local economy and the cultural practices associated with this activity are crucial to the identity of communities in the area [63].

From 2014, deep dredging accompanying the construction of the port and the closing of crucial fishing grounds sparked off significant local opposition and Lamu was placed on the WMF World Monuments Watch list. Various local community groups such as Save Lamu, the Lamu Youth Alliance and The Lamu Coastal Indigenous People's Right for Development became increasingly active in lobbying the Kenyan government to preserve the environmental, social and cultural integrity of the Lamu community (Figure 4). In 2018, the Kenyan High Court found the government had violated the residents' rights as they had not involved them in the project's design [64]. Significantly, this was seen as a violation of the indigenous residents 'right to culture' with the Lamu corridor project ordered to include a specific programme for public participation with Lamu residents on the project's impact on culture and how to mitigate adverse effects [65]. The court recognised traditional fishing rights as cultural rights and acknowledged their interdependence with other fundamental rights, ordering the government to pay over 17.5 million USD in compensation to 4600 fishermen in Lamu for loss of livelihood caused by the port development work. Despite this ruling, Lamu's rich MCH continues to be threatened with Lamu community groups currently protesting against the construction of a Chinese funded coal plant on the island and an offshore US funded wind farm. 


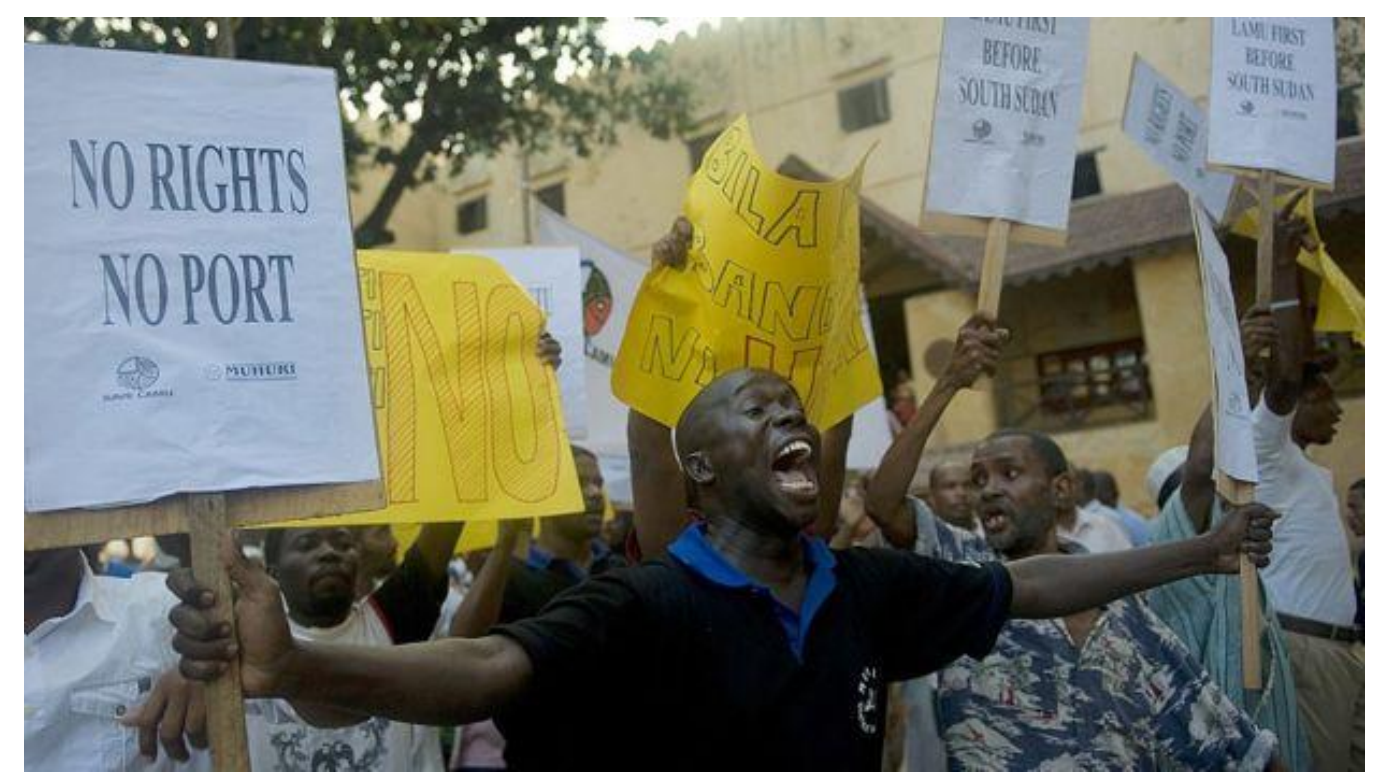

Figure 4. Lamu residents protest at the construction of a port at the historic town (Photo credit: ATP Tony Karumba).

The Lamu High Court ruling demonstrates that cultural heritage can play a vital role in redressing indigenous community rights, supporting individuals and communities to convey identities and values, fostering social inclusion and ensuring they have a say in infrastructural developments that directly affect their way of life. Indigenous coastal communities across the world are struggling to retain their sense of community and cultural identities as society undergoes rapid change associated with globalisation, development and disparity. These changes are contributing to their lack of 'voice' in important economic and cultural decisions affecting their lives and often undermining the intrinsic sustainability of these groups. The Lamu case highlights the importance of including local communities and their cultural heritage in development plans. Not only does this ensure that development is more inclusive, it creates fewer delays for developers and, most importantly, means that developments are more likely to be locally supported and therefore more sustainable. As the UN Development Programme notes ' $[\mathrm{g}]$ rowth can be inclusive and can eliminate poverty only if all segments of society, including the marginalized, share the benefits of development and participate in decision-making' [66].

Coastal regions around the world will need further infrastructural development as coastal populations increase. In this context, heritage needs to be recognised as an important resource with social, cultural and economic value that, rather than being a barrier to sustainable development, can work to make development more socially aware, ethical and effective.

\subsection{Development Aid Policy}

$\mathrm{MCH}$ has an important but so far completely unappreciated role to play in the long-term sustainability and ultimately the success of coastal and marine development. This is true as the development takes place but $\mathrm{MCH}$ should also be taken into consideration at the policy level when overseas aid agreements are made. Currently, $\mathrm{MCH}$ is not part of the international, national or local coastal development policy landscape, again contributing to social and economic under use of the resource and, worse, its destruction. Developmental aid and investment policies, as well as cultural heritage and coastal management approaches, need to avoid violations of the economic, social and cultural rights of vulnerable communities if they are to be successful.

A significant proportion of the estimated US \$23 billion funding for the Lamu Port-South Sudan-Ethiopia-Transport (LAPSSET) Corridor project (of which the Lamu port development is a part) comes from overseas aid. This is significant given the ethical obligations of aid-funded projects and, in particular, the responsibility of donor states not to violate human rights [67]. As access to cultural heritage 
is considered a human right (Article 27 of the Universal Declaration of Human Rights), it follows that cultural heritage should be considered when projects are funded and when they are curried out.

Certainly, it is common practice in most countries to carry out Environmental Impact Assessments (EIA) when infrastructural projects take place. However, the standard of these assessments and their ability to fully take account of cultural heritage is variable. Often, the heritage elements of such assessments are extremely limited, entirely desk-based and simply consider the impact on 'known' archaeological sites in the area without taking into account the potential existence of unrecorded sites (especially important in the marine zone where national datasets-where they exist-are far from complete) or, significantly, the wider impact of development on intangible cultural heritage perhaps the most crucial elements in terms of social cohesion, identity and well-being.

As the Lamu example demonstrates, infrastructural development projects need to avoid violations of the economic, social and cultural rights of vulnerable communities if they are to be successful. Development projects, especially where overseas aid funding is utilised, should be integrated and coherent with the past and present history of the local communities they impact-inclusive of the needs, expectations, and challenges faced by all groups within those communities (including all genders and minority groups). In coastal developments, an awareness of $\mathrm{MCH}$ can play an important role in issues related to identity, social cohesion and sense of place as well as providing usable data on how to better prevent and manage environmental risks.

Developmental aid success is usually measured against short-term visible economic gains at the expenses of broader long lasting social, cultural and environmental benefits-a consideration of $\mathrm{MCH}$ can help overcome this and ultimately ensure that any strategy put in place is more sustainable.

\subsection{Climate Change and Coastal Management}

Current marine biodiversity and the ecological composition of coastal environments are the result of sustained human action over millennia. It seems obvious that information from past human activity in the marine zone should therefore inform future human action in the zone. Despite this, data and perspectives from cultural heritage are usually not considered in current climate adaptation, resilience strategies and coastal management plans [68]. There is currently a disconnect between both heritage and climate science, and heritage and coastal management. Attention in the heritage sector has tended to focus on the impacts of climate change on the survival of marine heritage rather than what that heritage can do to inform future strategies to deal with climate and coastal change. Equally, scientists tend to overlook heritage research on the, often incorrect, assumption that it is purely narrative-based and qualitative rather than quantitative [69].

Tangible remains such as archaeological sites and landscapes contain information which is fundamental to understanding human responses to climate change over time and the development of coastal ecosystems. Equally, more intangible forms of heritage such as cultural beliefs and traditional knowledge can reveal valuable information on past climate change and adaption. Combining these sources with environmental archaeological science approaches such as sediment coring and faunal analyses can create baseline data sets that can be used to determine how modern conditions are shifting due to climate change.

The coastal regions of developing countries, and in particular SIDSs, are highly vulnerable areas worldwide due to their exposure to climatic change, high social vulnerability and low adaptive capacity [70]. Climatic and anthropogenic driven coastal change has serious implications for the sustainability of coastal ways of life, particularly the most vulnerable communities whose livelihoods often depend on exploiting natural resources [71].

Unfortunately, management strategies and conservation projects in these areas rely on short-term baseline data that, at best, cover little more than a century, when observational records began to be collected. As a result, projects and strategies put into place are limited as they do not fully reflect deep-rooted ecosystem dynamics or the relative resilience of different species to the effects of both human activities and changes driven by long-term climatic and other environmental factors. 
Despite being most susceptible to sea future sea level rise, most developing countries lack adequate reconstructions of past sea level changes and past human responses to those changes.

Data from $\mathrm{MCH}$ reflecting the full range of past human adaptation in the marine zone, including responses to extreme climatic events and sea level change, have the potential to improve the resolution and effectiveness of coastal and marine management strategies. Archaeological approaches can track how past behaviours, beliefs, technologies and societies interacted to create and respond to climatic conditions. For example, survey work on the northern Gulf coast of Florida has demonstrated how Indigenous peoples adapted to 5000 years of dramatic sea level rise and shoreline retreats by relocating their ancestors and ritual sites, changing their diets and even attempting to signal climate threats to future generations [72]. A recent project in England and Wales, Flood and Flow, explored how old place names reflected characteristics of the past landscape that can be used to map previous instances of the presence of water which can then be used to create more effective flood mitigation strategies [73].

Modelling of climatic variations over time and human responses to them using archaeological evidence creates a data set that can inform future management strategies and climatic predictions. While obviously not offering a complete solution, an enhanced understanding of the past exploitation of marine resources and ecosystems can inform the present use and future modelling of activity in coastal zones.

\subsection{Fishing}

Establishing sustainable fishing practices is a major aim of SDG14 and is essential for global food security with more than three billion people relying on fish for critical animal protein. In total, 300 million people depend on marine fisheries, the vast majority being linked to small-scale fisheries in developing countries. There is currently a lack of historical data on the human exploitation of marine resources, the scales of extraction, historic effects on marine biodiversity, and the environmental legacies of such practices over time. Archaeology can provide data on marine fauna exploitation and practice along coastal areas spanning millennia which can be used to inform future management strategies. For example, the identification of the most resilient species exploited by human groups in particular areas and conditions in the past or of indigenous species now absent that could be reintroduced is valuable information to strategies looking to rebuild overfished stocks.

As we have seen in the current situation at Lamu, as coastal development intensifies, the social traditions and cultural heritage of Indigenous fishing communities are increasingly under threat. Such communities are surviving repositories of traditional knowledge and practice, often maintaining fishing and craft traditions that have developed and endured over centuries. Whilst the richness of their $\mathrm{MCH}$ demands to be understood and recorded, these communities are usually amongst the poorest in the world. In addition, the effects of human-induced climate change, marine pollution and over-fishing have in many cases made their current practices unsustainable, making finding new sources of income for fishing communities an emerging priority. Simple preservation of their ways of life is not an option and would only at best serve to fossilise them in poverty.

One of the biggest challenges we face is balancing preservation and development. This is not easy and requires anthropological work alongside the co-creation and co-production of solutions with the communities themselves. To date, aid interventions have tended to be scientific and practical in approach ignoring cultural sensitivities and traditions. The wider cultural concerns and context of $\mathrm{MCH}$ could have a real value here in ensuring not only that solutions are identified but that they are accepted and supported by local communities.

At present, modern fisheries management strategies tend to be implemented by governments using scientific approaches that are insensitive to local conditions and fail to address the core concerns of fishing communities resulting in a lack of local support and uptake [74]. Effective solutions need to be culturally aware, incorporating and recognising past practices to bridge the gap between modern scientific knowledge and traditional maritime knowledge. The latter has been passed down for generations and much of it will be relevant to the sustainable management of fisheries and other 
marine natural resources. Moreover, because the ideas come from the communities themselves, they are much more likely to be respected, as recent cases from the Pacific islands have illustrated [75].

\subsection{Offshore Industry}

Offshore wind energy, oil and natural gas projects rarely take account of submerged heritage in developing country contexts usually due to a lack of information on existing sites and national capacity. As with coastal development, an argument could be made that offshore work also has a responsibility to respect the rights of the host country to access their heritage. Although marine industries are becoming better regulated under national and international frameworks, submerged heritage sites need better monitoring, documentation and enhancement to be of use to local and national stakeholders. The offshore marine industries regularly use survey and mapping technologies that could facilitate the identification and recording of submerged heritage. By employing the leading-edge technologies used by the offshore marine industry, there is genuine potential to develop $\mathrm{MCH}$ professional capacity in developing countries. Extraction projects that take some account of submerged heritage will ensure that benefits to the host country continue long after the projects are completed. Information about fragile heritage on the seabed is also needed in planning other marine activities such as cabling, dredging, fish farming, extracting gravel, laying pipelines, and renewable energy platform building. Developing the seabed in a way that facilitates the research of $\mathrm{MCH}$ (particularly submerged landscapes) depends on the collaboration between industry and national authorities, where $\mathrm{MCH}$ is seen as an asset to development rather than an obstacle.

\section{MCH, SDG 14 and the Wider 2030 Agenda}

$\mathrm{MCH}$ has an important but so far completely unappreciated role to play in sustainable ocean management initiatives and in the wider success of coastal and marine development. This human dimension should be seen as crucial in evidence-based decision-making across the coastal and marine sectors capable of informing, as we have seen, Blue Economy initiatives such as heritage tourism, coastal and offshore development projects, coastal management and climate change mitigation strategies, fisheries management, as well as having a role in marine ecosystem conservation, marine spatial planning, policy making and ocean governance more widely.

As a usable knowledge base that can address development challenges, and contribute directly to the sustainable and inclusive prosperity of coastal peoples and SIDS, the inclusion of MCH in approaches related to SDG14 is essential. As we have seen, $\mathrm{MCH}$ has a clear role to play in informing the effective management of marine and coastal ecosystems (SDG 14.2 and 14.5); in the development of sustainable fishing strategies (SDG 14.4; 14.B), especially in harnessing and including existing traditional knowledge and past human exploitation strategies; in 'the sustainable use of marine resources, including through sustainable management of tourism' (SDG 14.7); in the push to 'increase scientific knowledge, develop research capacity and transfer marine technology' (SDG14.A); and in strategies to 'enhance the conservation and sustainable use of oceans and their resources by implementing international law' (SDG 14.C), particularly through the ratification and implementation of the 2001 Convention on the Protection of the Underwater Cultural Heritage.

However, just as the promotion of healthy oceans and the sustainable use of marine resources cuts across the Sustainable Development Goal agenda more widely, the utility of $\mathrm{MCH}$ has a wider applicability. As Nilsson et al. (2016) have convincingly argued, it is the interactions between the SDGs that are key to the overall success of the 2030 Agenda to create a smarter, wider and more sustainable future. Reducing the impact of human activity on marine ecosystems is not solely dependent on initiatives around SDG 14 but also on achieving success in other SDGs. For example, considering $\mathrm{MCH}$ in SDG 14 approaches forms part of the wider aim 'to protect the world's cultural and natural heritage' (SDG 11.4). Equally ocean health is clearly related to the health of the terrestrial ecosystem (SDG 15) and positive action on climate change (SDG 13). Identifying the economic potential of $\mathrm{MCH}$ can help to alleviate poverty (SDG 1) while access to cultural heritage promotes general human wellbeing (SDG 3). 
Using MCH data sets to enhance coastal and marine ecosystem resilience will help reduce pollution and build healthy fish stocks, contributing to freshwater quality (SDG 6) and food security (SDG2) and lessening the impact of future climate change (SDG 13). The sustainable use of $\mathrm{MCH}$ resources and knowledge can also contribute to creating decent work and economic growth (SDG 8) through employment in 'Blue Economy' sectors such as fisheries and coastal tourism.

$\mathrm{MCH}$ is a unique and strongly engaging medium to engage public audiences in historic narratives: shipwrecks, submerged settlements and ports can be used to convey a better understanding not only of specific histories, but also of climate change, commerce and the wider evolution of societies and their place in the world [76]. Providing access to $\mathrm{MCH}$, and the research created around it, will help to promote free and lifelong access to educational resources (SDG4). By democratising access to educational resources through grass-roots work with community groups, individuals and NGOs, $\mathrm{MCH}$ can help promote equal gender opportunities (SDG5) in education. Equally, through historic parallels it can help promote the participation of women in marine food producing strategies [77].

More widely, $\mathrm{MCH}$ can help promote ethical development through recognising the role of $\mathrm{MCH}$ in overseas aid-funded marine infrastructure and offshore industry projects (SDGs 16 and 17). Having an $\mathrm{MCH}$ element to marine coastal infrastructure and offshore projects allows social and cultural benefits to continue to be created after projects have finished, building resilience into those activities and therefore enhancing the effectives of overseas aid (SDG 9).

\section{MCH as a Facilitator for Sustainable and Ethical Development}

Heritage has the power to interest local groups and effect community level change while at the same time engage at national and international levels to influence wider practice. As such, $\mathrm{MCH}$ has the power to link human activities taking place in the marine zone-it provides context for present action in that space and, crucially, it can contribute useful data for future action. Knowledge and practice from the past should be used to inform future development strategies, engaging and connecting local communities and marine stakeholders to create more effective solutions to real challenges on the ground (Figure 5).

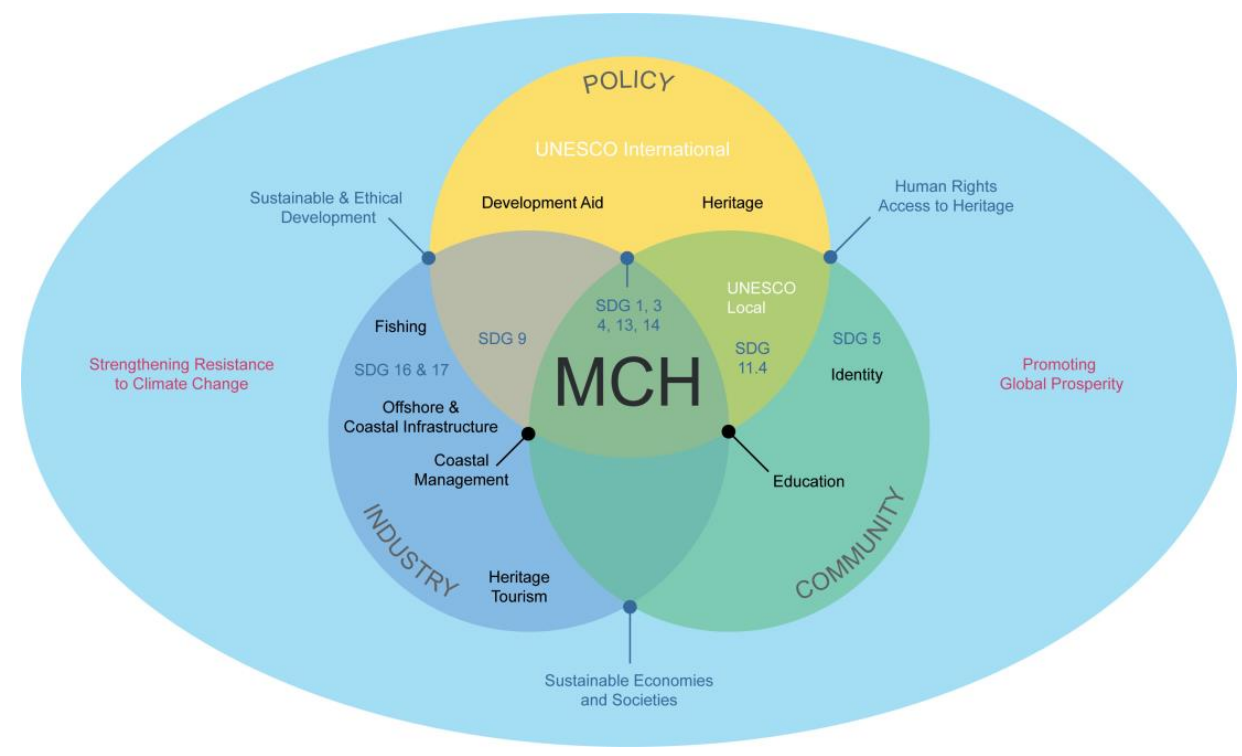

Figure 5. $\mathrm{MCH}$ can unite a range of sustainable activities and approaches in the marine zone. Activities such as heritage tourism, coastal development, infrastructure work, sustainable fishing initiatives, legal approaches and governance can all be linked and given context by heritage-these are practices carried out by people in the present building on the practice of the past.

The lack of consideration of $\mathrm{MCH}$ is part of the failure inherent in the language of the SDGs more widely to link culture and environment together [78]. Calls for adopting the term 'biocultural 
heritage' which more fully reflect the diverse and nuanced relationships between communities and their local environments are convincing [79]. $\mathrm{MCH}$, as it is defined in this paper, could easily be seen as the marine expression of a wider Biocultural Heritage $(\mathrm{BCH})$ approach where cultural heritage encompasses language, cultural memory, traditional ecological knowledge and the values of local and indigenous communities interrelated and indivisible from the biogenetic diversity of landscapes [80].

In a very real sense, responding to global challenges is breaking down the boundaries between academic subjects to create new interdisciplinary approaches. That said, we should still perhaps be careful about the terminology we use and what its use may infer. The idea of cultural heritage is a Western one and is a term that may not translate well into different cultural contexts. $\mathrm{MCH}$ is not inherently sensitive of local traditions and practices and could easily become an agent of neo-colonialism if it does not encompass its own critique of current (marine) heritage management approaches [81].

That said, considering knowledge and data from marine heritage when devising sustainable marine management initiatives is not simply advisable-it is essential. Without a cultural element, it is unlikely that any initiative will be truly sustainable. There have been many examples of successful interdisciplinary collaborations between archaeologists, ocean scientists, policy makers and other marine stakeholders including the Archaeological and Biological Analysis of WW II wrecks in the Gulf of Mexico [82], MACHU (Managing Cultural Heritage Underwater) [83], WreckProtect [84], SASMAP (Development of tools and techniques to Survey, Assess, Stabilise, Monitor and Preserve underwater archaeological sites) [85], SPLASHCOS (Submerged Prehistoric Archaeology and Landscapes of the Continental Shelf) [86] and the CBDAMM (Capacity Building of Data Acquisition Management Methods) Project [87]. Most recently, the Rising from the Depths $\mathrm{MCH}$ initiative began in Eastern Africa [88]. Rising from the Depths is an interdisciplinary network, funded by the UK GCRF, looking to identify how the submerged and coastal cultural heritage of Kenya, Tanzania, Mozambique and Madagascar can stimulate ethical, inclusive and sustainable economic growth in the region. Collaboration between marine archaeologists and ocean scientists is an essential part of this initiative-UNESCO, the Western Indian Ocean Maritime Science Association, Kenya Marine and Fisheries Research Institute and the Society for Underwater Technology are project partners and amongst its portfolio the network is directly funding projects looking at how traditional knowledge and heritage data can enhance marine ecosystem management, sustainable fishing practices and inform responses to coastal pollution and climate change. The task ahead, therefore, is to ensure that the potential of $\mathrm{MCH}$ is recognised and fully integrated into sustainable development approaches in the decade running up to 2030 [89].

\section{Conclusions}

The future of maritime archaeology should not simply be about individual wrecks, individual projects or discoveries (although this will continue), it should be about raising awareness of the importance of the sea and water contact in general-both in terms of human development in the past and in terms of how we develop in the future. The SDG agenda has provided the opportunity to generate a step-change in the ambition and academic profile of Marine Cultural Heritage, where it can be established as an interdisciplinary field of research with major social, economic and cultural significance.

Over the coming century, a number of major archaeological discoveries will come from the sea. In many ways, the future of archaeology lies underwater but equally the future of ocean management and sustainable development needs to have a deep time perspective informed by our shared human past if it is to be successful-we need to respect the cultural traditions of communities who have lived by the sea for millennia. Using the past as a resource, we need to create a new way of living in concert with the sea which also considers the needs of future generations.

A Marine Cultural Heritage outlook (prioritising human interaction with the sea in all its diversity) could provide the conceptual framework that unites, stimulates and informs interdisciplinary responses to the challenges set out in SDG 14. Such an outlook provides a unity to the coastal and marine 
zone, created by combining conceptions of the natural and human environment, where different approaches can come together to create more inclusive and therefore ultimately more sustainable solutions to current challenges. Marine Cultural Heritage is not simply about archaeology, history, ecology, geography, natural science, coastal management or climate change, it is about all of these aspects and how societies can come together, negotiate and mediate these different approaches into real solutions.

Funding: This work was funded by the Arts and Humanities Research Council [grant number AH/R005443/1] through the GCRF Network+ Rising from the Depths.

Acknowledgments: This article is based on a paper I presented on the 5th June 2017 at the United Nations Ocean Conference in New York supporting the implementation of SDG 14 'Life Below Water' to raise awareness of the role marine cultural heritage can play in the sustainable development of the oceans. I would like to thank Ulrike Guerin, Programme Specialist at UNESCO for the 2001 Convention on the Protection of the Underwater Cultural Heritage, for inviting me to attend and for organising the UNESCO Underwater Cultural Heritage side event at the UN conference. The content of the paper has since grown through discussion with various colleagues over the past two years and I would especially like to thank Annamaria La Chimia, Antony Firth, Della Scott-Ireton, Athena Trakadas and Yvonne Shashoua for reading and commenting on the paper in draft.

Conflicts of Interest: The author declares no conflict of interest.

\section{References}

1. United Nations. Transforming Our World: The 2030 Agenda for Sustainable Development; United Nations, Department of Economic and Social Affairs: New York, NY, USA, 21 October 2015. Available online: https: //www.unfpa.org/sites/default/files/resource-pdf/Resolution_A_RES_70_1_EN.pdf (accessed on 23 May 2019).

2. FAO (Food and Agriculture Organisation of the United Nations). FAO Working for SDG 14: Healthy Oceans for Food Security, Nutrition and Resilient Communities; FAO: Rome, Italy, 2017.

3. UNESCO. Revised Roadmap for the UN Decade of Ocean Science for Sustainable Development; IOC/EC-LI/2 Annex 3; UNESCO: Paris, France, 2019. Available online: https://unesdoc.unesco.org/ark:/48223/pf0000265141 (accessed on 25 July 2019).

4. Wells, H.G. A Short History of the World; Penguin Classics: London, UK, 2006. (first published 1922).

5. Hart-Davis, A. History: From the Dawn of Civilization to the Present Day; Doring Kinderlsey: London, UK, 2006.

6. Black, J. A History of the World: From Prehistory to the 21st Century; Arcturus: London, UK, 2018.

7. Bass, G. Archaeology under Water; Thames and Hudson: New York, NY, USA, 1996.

8. Adams, J.; Rönnby, J. Landscapes, Seascapes and Shipscapes. In Interpreting Shipwrecks. Maritime Archaeological Approaches; Södertörn Academic Studies 56, Southampton Archaeology Monographs New Series No. 4, Adams, J., Rönnby, J., Eds.; The Highfield Press: Southampton, UK, 2013; pp. 1-8.

9. Flatman, J. Cultural biographies, cognitive landscapes and dirty old bits of boat: 'Theory' in maritime archaeology. Int. J. Naut. Archaeol. 2013, 32, 143-157.

10. UNESCO. Convention on the Protection of the Underwater Cultural Heritage; UNESCO: Paris, France, 2001. Available online: http://www.unesco.org/new/en/culture/themes/underwater-cultural-heritage/2001-convent ion/ (accessed on 29 April 2019).

11. Vadi, V. Investing in Culture: Underwater Cultural Heritage and International Investment Law. Vanderbilt J. Transnatl. Law 2009, 42, 853-904.

12. Westerdahl, C. The maritime cultural landscape. Int. J. Naut. Archaeol. 1992, 21, 5-14. [CrossRef]

13. McGrail, S. Studies in Maritime Archaeology; British Archaeological Reports: Oxford, UK, 1997.

14. Hunter, J.R. 'Maritime Culture': Notes from the Land. Int. J. Naut. Archaeol. 1994, 23, 261-264.

15. O'Sullivan, A. Place, Memory and Identity among Estuarine Fishing Communities: Interpreting the Archaeology of Early Medieval Fish Weirs. World Archaeol. 2003, 35, 449-468. [CrossRef]

16. Westerdahl, C. The Maritime Cultural Landscape. In The Oxford Handbook of Maritime Archaeology; Catsambis, A., Ford, B., Hamilton, D., Eds.; Oxford University Press: Oxford, UK, 2013; pp. 733-762.

17. Bednarik, R.G. The Beginnings of Maritime Travel. Adv. Anthropol. 2014, 4, 209-221. [CrossRef]

18. Bailey, G.N. World prehistory from the margins: The role of coastlines in human evolution. J. Interdiscip. Stud. Hist. Archaeol. 2004, 1, 39-50. 
19. Bailey, G. Continental shelf archaeology: Where next? In Submerged Prehistory; Benjamin, J., Bonsall, C., Pickard, K., Fischer, A., Eds.; Oxbow: Oxford, UK, 2011; pp. 311-331.

20. Sturt, F.; Flemming, N.C.; Carabias, D.; Jöns, H.; Adams, J. The next frontiers in research on submerged prehistoric sites and landscapes on the continental shelf. Proc. Geol. Assoc. 2018, 129, 654-683. [CrossRef]

21. IOC. The Science We Need for the Ocean We Want: The United Nations Decade of Ocean Science for Sustainable Development (2021-2030); IOC: New Delhi, India, 2018. Available online: https://unesdoc.unesco.org/ark: /48223/pf0000265198 (accessed on 24 January 2019).

22. World Bank. The Potential of the Blue Economy-Increasing Long-Term Benefits of the Sustainable Use of Marine Resources for Small Island Developing States and Coastal Least Developed Countries; World Bank: Washington, DC, USA, 2017. Available online: http://hdl.handle.net/10986/26843 (accessed on 22 June 2018).

23. WWF. Principles for a Sustainable Blue Economy. WWF Baltic Ecoregion Programme 2015; WWF: Gland, Switzerland. Available online: http://wwf.panda.org/?247477/Principles-for-a-Sustainable-Blue-Economy (accessed on 23 March 2019).

24. World Bank Blue Economy. Development Framework-Growing the Blue Economy to Combat Poverty and Accelerate Prosperity; World Bank Blue Economy: Washington, DC, USA, April 2016. Available online: http://pubdocs. worldbank.org/en/446441473349079068/AMCOECC-Blue-Economy-Development-Framework.pdf (accessed on 23 March 2019).

25. World Bank and United Nations Department of Economic and Social Affairs. The Potential of the Blue Economy: Increasing Long-term Benefits of the Sustainable Use of Marine Resources for Small Island Developing States and Coastal Least Developed Countries; World Bank: Washington, DC, USA, 2017. Available online: https://openknowledge.worldbank.org/handle/10986/26843 (accessed on 23 March 2019).

26. Patil, P.G.; Diez, S.M. Grenada-Blue Growth Coastal Master Plan; World Bank Group: Washington, DC, USA, 2016. Available online: http://documents.worldbank.org/curated/en/358651480931239134/Grenada-Blue-gro wth-coastal-master-plan (accessed on 25 February 2019).

27. ICIA (Independent Commission for Aid Impact). How DFID Works with Multilateral Agencies to Achieve Impact; Report 44; ICIA: London, UK, June 2015; p. 21. Available online: https://icai.independent.gov.uk/wp-content /uploads/ICAI-Report-How-DFID-works-with-multilateral-agencies-to-achieve-impact.pdf (accessed on 7 October 2018).

28. WTO. Cultural Heritage and Tourism Development; World Tourism Organisation: Madrid, Spain, 2001. Available online: https://www.e-unwto.org/doi/book/10.18111/9789284404841 (accessed on 15 May 2019).

29. Gražulevičiūtè, I. Cultural Heritage in the Context of Sustainable Development. Environ. Res. Eng. Manag. 2006, 3, 74-79.

30. Richards, G. Cultural Tourism: A review of recent research and trends. J. Hosp. Tour. Manag. 2018, 36, 12-21. [CrossRef]

31. UNESCO. UNESCO World Heritage and Sustainable Tourism Programme; UNESCO: Paris, France, 2017. Available online: http://whc.unesco.org/en/tourism/ (accessed on 16 July 2018).

32. Jeffery, B. Realising the cultural tourism potential of South Australian shipwrecks. Hist. Environ. 1990, 7, 72-76.

33. Mesić, J. A Resource for Sustainable Development: The case of Croatia. Mus. Int. Underw. Cult. Herit. 2008, 60, 91-99. [CrossRef]

34. Cohn, A.; Dennis, J. Maritime Archaeology, the Dive Community, and Heritage Tourism. In The Oxford Handbook of Maritime Archaeology; Catsambis, A., Ford, B., Hamilton, D., Eds.; Oxford University Press: New York, NY, USA, 2011; pp. 1055-1081.

35. Kean, J. SS Thistlegorm: The True Story of the Red Sea's Greatest Shipwreck; Revised New Special Edition; Fatid Atiya Press: Cairo, Egypt, 2009.

36. Smith, T. Shipwreck trails: Public ownership of a unique resource? An Australian perspective. In Submerged Cultural Resource Management: Preserving and Interpreting Our Maritime Heritage; Spirek, J.D., Scott-Ireton, D.A., Eds.; Kluwer Academic/Plenum Publishers: New York, NY, USA, 2003; pp. 121-133.

37. Beattie-Edwards, M. The Local Economic Value of a Protected Wreck; Nautical Archaeology Society for English Heritage: Swindon, UK, 2013.

38. Stefanile, M. Underwater Cultural Heritage, Tourism and Diving Centers: The case of Pozzuoli and Baiae (Italy). In Proceedings of the IKUWA V the 5th International Congress on Underwater Archaeology, A Heritage for Mankind, Cartagena, Colombia, 15-18 October 2014; pp. 213-224. 
39. James, A. Review of the Virtual Dive Trails Scheme (7374): A Big Splash or a Damp Squib? Historic England Report; Historic England: Swindon, UK, March 2018.

40. UNESCO. Underwater Cultural Heritage and Small Island Developing States. In Proceedings of the 3rd UN International Conference on Small Island Developing States, Apia, Samoa, 1-4 September 2014; Final Report 2014.

41. UNESCO. The Benefit of the Protection of Underwater Cultural Heritage for Sustainable Growth, Tourism and Urban Development. Available online: http://www.unesco.org/new/fileadmin/MULTIMEDIA/HQ/CLT/pdf/UCH_d evelopment_study_2013.pdf (accessed on 14 February 2019).

42. UNESCO. Submerged Archaeological Sites: Commercial Exploitation Compared to Long-Term Protection. Secretariat of the UNESCO Convention on the Protection of the Underwater Cultural Heritage. Available online: http://www.unesco.org/new/fileadmin/MULTIMEDIA/HQ/CLT/pdf/UCH\%20Commercial\%20Expl oitation\%20versus\%20Protection_07.pdf (accessed on 17 November 2018).

43. Throckmorton, P. The World's Worst Investment: The Economics of Treasure Hunting with Real Life Comparisons. In Maritime Archaeology: A Reader of Substantive and Theoretical Contributions; Babits, L.E., Tilburg, H.V., Eds.; The Springer Series in Underwater Archaeology; Springer: New York, NY, USA, 1998; pp. 75-83.

44. Mary Rose Trust. Annual Review; Mary Rose Trust: Portsmouth, UK, 2017. Available online: https: //maryrose.org/annual-reports/ (accessed on 27 February 2019).

45. SS Great Britain Trust. Annual Review 2013; SS Great Britain Trust: Bristol, UK, 2014.

46. WFF. Beautiful Coastlines Disappearing under Concrete; World Wildlife Fund: Gland, Switzerland. Available online: https://wwf.panda.org/our_work/oceans/problems/tourism/ (accessed on 27 March 2019).

47. Coll, M.; Piroddi, C.; Albouy, C.; Lasram, F.B.R.; Cheung, W.W.L.; Christensen, V.; Karpouzi, V.S.; Guilhaumon, F.; Mouillot, D. The Mediterranean Sea under siege: Spatial overlap between marine biodiversity, cumulative threats and marine reserves. Glob. Ecol. Biogeogr. 2012, 21, 465-480. [CrossRef]

48. Radić Rossi, I. Underwater Cultural Heritage and Maritime Archaeology in Croatia: An Overview. Eur. J. Archaeol. 2012, 15, 285-308. [CrossRef]

49. World Tourism Organization. Challenges and Opportunities for Tourism Development in Small Island Developing States; UNWTO: Madrid, Spain, 2012.

50. Crossland, C.; Baird, D.; Ducrotoy, J.-P.; Lindeboom, H.; Buddemeier, R.; Dennison, W. The Coastal Zone-A Domain of Global Interactions. In Coastal Fluxes in the Anthropocene; Crossland, C., Kremer, H., Lindeboom, H., Marshall Crossland, J., Tissier, M.A., Eds.; Springer: Berlin, Heidelberg, Germany, 2005; pp. 1-37.

51. Patterson, M.; Hardy, D. Economic Drivers of Change and their Oceanic-Coastal Ecological Impacts. In Ecological Economics of the Oceans and Coasts; Patterson, M., Glavovic, B.C., Eds.; Edward Elgar Publishing: Cheltenham, UK, 2008; pp. 187-209.

52. Neumann, B.; Vafeidis, A.T.; Zimmermann, J.; Nicholls, R. Future Coastal Population Growth and Exposure to Sea-Level Rise and Coastal Flooding-A Global Assessment. PLoS ONE 2015, 10, e0118571. [CrossRef]

53. McGranahan, G.; Balk, D.; Anderson, B. The rising tide: Assessing the risks of climate change and human settlements in low elevation coastal zones. Environ. Urban. 2007, 19, 17-37. [CrossRef]

54. Xu-Zhao, J.; Tie-Ying, L.; Chi-Wei, S. China's marine economy and regional development. Mar. Policy 2014, 50, 227-237.

55. Erickson, A.S.; Bond, K. Archaeology and the South China Sea; The Diplomat: Tokyo, Japan, 2015. Available online: https:/thediplomat.com/2015/07/archaeology-and-the-south-china-sea/ (accessed on 11 July 2018).

56. JTP. China Dalian Diamond Bay, China Major City Development Masterplan: Celebrating E Embracing the Waterfront; JTP: London, UK, 2001. Available online: https://www.jtp.co.uk/cms/pdfs/Dalian-Diamond-Bay-China.pdf (accessed on 11 July 2018).

57. Dong, L. Waterfront Development: A Case Study of Dalian. Master of Applied Environmental Studies in Local Economic Development-Tourism Policy and Planning. Master's Thesis, University of Waterloo, Waterloo, ON, Canada, 2004.

58. Sharma, B.K.; Das Kundu, N. China's One Belt One Road: Initiative, Challenges and Prospects; VIJ Books (India) Pty Limited: Delhi, Indian, 2016. 
59. ICOMOS. The Stockholm Declaration: Declaration of ICOMOS Marking the 50th Anniversary of the Universal Declaration of Human Rights; ICOMOS: Paris, France, 1998. Available online: https://www.icomos.org/en/what-we-do/focus/human-rights-and-world-heritage/179-articles-en-f rancais/ressources/charters-and-standards/372-the-stockholm-declaration (accessed on 24 July 2019).

60. Ghaidan, U. Lamu: A study of the Swahili Town; East African Literature Bureau: Nairobi, Kenya, 1975.

61. UNESCO. Report on the Reactive Monitoring Mission to Lamu Old Town, Kenya from 9 to 11 February 2015; Final Report 2015; UNESCO: Paris, France, 2015. Available online: https://whc.unesco.org/document/135436/ (accessed on 10 May 2018).

62. Government of Kenya. Kenya Vision 2030: A Globally Competitive and Prosperous Kenya; Ministry of Planning \& National Development and Vision 2030; Government Printer: Nairobi, Kenya, 2007.

63. UNESCO. Community Members in Lamu World Heritage Site in Kenya Begin an Urgent Community-Based Inventory and Digital Archive of the Island's Intangible Cultural Heritage; UNESCO Office in Nairobi: Nairobi, Kenya, 16 October 2018. Available online: http://www.unesco.org/new/en/member-states/single-view/news/communi ty_members_in_lamu_world_heritage_site_in_kenya_begin/ (accessed on 1 February 2019).

64. Republic of Kenya. High Court Petition no 22 of 2012. 2018. Available online: https://naturaljustice.org/wpcontent/uploads/2018/05/Final-Judgment.pdf (accessed on 22 April 2019).

65. Lwanga, C. Court orders State to pay Lamu fishermen Sh1.7bn in Lapsset compensation. Business Daily (Kenya). 1 May 2018. Available online: https://www.businessdailyafrica.com/news/Court-orders-State-to-p ay-Lamu-fishermen-Sh1-7bn-over-Lapsset/539546-4538748-5wslscz/index.html (accessed on 1 Feb 2019).

66. United Nations Development Programme. Development planning and inclusive sustainable growth. Available online: https://www.undp.org/content/undp/en/home/sustainable-development/development-pl anning-and-inclusive-sustainable-growth.html (accessed on 25 May 2019).

67. Dasandi, N.; Erez, L. The Donor's Dilemma: International Aid and Human Rights Violations. Br. J. Political Sci. 2017, 1-22. [CrossRef]

68. ICOMOS Climate Change and Cultural Heritage Working Group. The Future of Our Pasts: Engaging Cultural Heritage in Climate Action 1 July 2019; ICOMOS: Paris, France, 2019. Available online: https:/www.icomos.org/en/get-involved/image-get-involved/77-articles-en-francais/59522-icomos-r eleases-future-of-our-pasts-report-to-increase-engagement-of-cultural-heritage-in-climate-action (accessed on 12 July 2019).

69. Adger, W.N.; Barnett, J.; Katrina Brown, B.; Marshall, N.; O’Brien, K. Cultural dimensions of climate change impacts and adaptation. Nat. Clim. Chang. 2013, 3, 112-117. [CrossRef]

70. Niang, I.; Ruppel, O.C.; Abdrabo, M.A.; Essel, A.; Lennard, C.; Padgham, J.; Urquhart, P. Africa, Climate Change 2014: Impacts, Adaptation and Vulnerability; Contributions of Working Group II to the Fifth Assessment Report of the Intergovernmental Panel on Climate Change 2014; Cambridge University Press: Cambridge, UK, 2017; pp. 1199-1265.

71. Esteves, L.S.; Ballesteros, C. Building an index of exposure to coastal change in Eastern Africa with applications to conservation of cultural heritage. In Coastal Sediments 2019, Proceedings of the 9th Annual Conference; Wang, P., Rosati, J.D., Vallee, M., Eds.; World Scientific Publishing Co.: Singapore, 2019; pp. 1063-1076.

72. Sassaman, K.E.; Wallis, N.J.; McFadden, P.S.; Mahar, G.J.; Jenkins, J.A.; Donop, M.C. Keeping Pace with Rising Sea: The First 6 Years of the Lower Suwannee Archaeological Survey, Gulf Coastal Florida. J. Coast. Isl. Archaeol. 2016, 12, 173-199. [CrossRef]

73. Jones, R. Responding to Modern Flooding: Old English Place-Names as a Repository of Traditional Ecological Knowledge. J. Ecol. Anthropol. 2016, 18, 9. [CrossRef]

74. Nielsen, J.R.; Degnbola, P.; Kuperan Viswanathan, K.; Ahmed, M.; Hara, M.; Mustapha Raja Abdullah, N. Fisheries co-management-An institutional innovation? Lessons from South East Asia and Southern Africa. Mar. Policy 2004, 28, 151-160. [CrossRef]

75. Hanich, Q.; Teo, F.; Tsamenyia, M. A collective approach to Pacific islands fisheries management: Moving beyond regional agreements. Mar. Policy 2010, 34, 85-91. [CrossRef]

76. Firth, A. The Social and Economic Benefits of Marine and Maritime Cultural Heritage: Towards Greater Accessibility and Effective Management; Fjordr Limited for Honor Frost Foundation: London, UK, 2015.

77. Alonso-Población, E.; Siar, S.V. Women's Participation and Leadership in Fisherfolk Organizations and Collective Action in Fisheries: A Review of Evidence on Enablers, Drivers and Barriers; Food and Agricultural Organization of the United Nations: Bangkok, Thailand, 2018. 
78. Díaz, S.; Demissew, S.; Carabias, J.; Joly, C.A. The IPBES conceptual framework-connecting nature and people. Curr. Opin. Environ. Sustain. 2015, 14, 1-16. [CrossRef]

79. Poole, A.K. Where is Goal 18? The Need for Biocultural Heritage in the Sustainable Development Goals. Environ. Values 2018, 27, 55-80. [CrossRef]

80. Gavin, M.C.; McCarter, J.; Mead, A.; Berkes, F.; Stepp, J.R.; Peterson, D.; Tang, R. Defining biocultural approaches to conservation. Trends Ecol. Evol. 2015, 30, 140-145. [CrossRef]

81. Hutchings, R.M. Maritime Heritage in Crisis. Indigenous Landscapes and Global Ecological Breakdown; Routledge: New York, NY, USA; London, UK, 2017.

82. Church, R.; Warren, D.; Cullimore, R.; Johnston, L.; Schroeder, W.; Patterson, W.; Shirley, T.; Kilgour, M.; Morris, N.; Moore, J. Archaeological and Biological Analysis of World War II Shipwrecks in the Gulf of Mexico: Artificial Reef Effect in Deep Water; OCS Study MMS 2007-015; U.S. Dept. of the Interior, Minerals Management Service (now Bureau of Ocean Energy Management), Gulf of Mexico OCS Region: New Orleans, LA, USA, 2007. Available online: https://www.boem.gov/ESPIS/4/4239.pdf (accessed on 20 July 2019).

83. Manders, M.; Oosting, R.; Brouwers, W. MACHU Final Report; Educom Publishers BV: Rotterdam, The Netherlands, 2009.

84. Björdal, C.G.; Gregory, D. Wreck Protect. Decay and Protection of Archaeological Wooden Ship-Wrecks; Archaeopress: Oxford, UK, 2011.

85. Gregory, D.; Manders, M. Best Practices for Locating, Surveying, Assessing, Monitoring and Preserving Underwater Archaeological Sites; SASMAP Guideline Manual 2. SASMAP Project: Amersfoort, The Netherlands, 2015.

86. Flemming, N.C.; Çağatay, M.N.; Chiocci, F.L.; Galanidou, N.; Jöns, H.; Lericolais, G.; Missiaen, T.; Moore, F.; Rosentau, A.; Sakellariou, D.; et al. Land Beneath the Waves: Sub-Merged Landscapes and Sea Level Change. A Joint Geoscience-HUMANITIES strategy for European Continental Shelf Prehistoric Research; Position Paper 21 of the European Marine Board: Ostend, Belgium, 2014.

87. Trakadas, A.; Mhammdi, N. Recommendations for Best Practices in Data Acquisition Methods for Natural and Cultural Heritage Management of Moroccan Coastal Wetlands/Recommandations Pour les Bonnes Pra-Tiques en Matière de Méthodes D'acquisition de Données Pour la Gestion du Patrimoine Naturel et Culturel des Zones Humides Côtières Marocaines; Archaeopress: Oxford, UK, 2018.

88. RftD Rising from the Depths. Utilising Marine Cultural Heritage in East Africa to Help Develop Sustainable Social, Economic and Cultural Benefits. 2017. Available online: https://risingfromthedepths.com (accessed on 10 June 2019).

89. Trakadas, A.; Firth, A.; Gregory, D.; Elkin, D.; Guerin, U.; Henderson, J.; Kimura, J.; Scott-Ireton, D.; Shashoua, Y.; Underwood, C.; et al. The Ocean Decade Heritage Network: Integrating cultural heritage within the UN Decade of Ocean Science 2021-2030. J. Marit. Archaeol. 2019, 14, 153-165. [CrossRef] 